\title{
Analisis Faktor-Faktor Yang Mempengaruhi Tingkat Pendapatan Wanita Di Kota Jambi
}

\author{
oleh : \\ *) Rika Neldawaty, S.E., MS.Ak., Akt. \\ *) Iwan Eka Putra, S.E., M.M. \\ **)Dosen Tetap STIE Muhammadiyah Jambi
}

\begin{abstract}
Abstrak
Kontribusi wanita bekerja sangat tinggi di kota Jambi Sebagai individu, perempuan juga memiliki harapan-harapan, kebutuhan-kebutuhan, minat dan potensi yang menekankan nilai positif manusia. Perempuan juga membutuhkan aktualisasi diri yang seoptimal mungkin demi pengembangan dirinya, sesuatu pada akhirnya juga membawa dampak positif pada pengembangan umat manusia secara umum. Perempuan yang jumlahnya lebih dari setengah jumlah penduduk dapat menjadi sumber daya manusia yang sangat potensial bagi pembangunaan masyarakat dan bangsa.
\end{abstract}

Kata Kunci : Pendapatan Wanita, Pendidikan, Status Perkawinan

\section{A. PENDAHULUAN}

\section{Latar Belakang}

Perkembangan teknologi di luar sektor pertanian umumnya dapat menciptakan lapangan kerja baru. Kesempatan ini selain dimanfaatkan oleh masyarakat kota juga dimanfaatkan oleh masyarakan desa. Peningkatan pembangunan sarana jalan raya dan transportasi mendorong arus migrasi dari desa ke kota untuk memanfaatkan kesempatan kerja di sektorjasa, perdagangan, konstruksi, dan industri. Bersamaan dengan peningkatan kesempatan kerja ini maka muncul kesempatan kerja yang lain yang berupa kegiatan yang disebut sektor informal.

Menurut Sitorus (1994), seluruh kasus rumah tangga miskin menerapkan strategi nafkah ganda; yaitu tidak mengharapkan hanya dari satu pekerjaan melainkan dari beberapa macam pekerjaan tergantung musim dan kesempatan. Melihat kenyataan tersebut, maka pengembangan kegiatan di dalam dan di luar sektor pertanian perlu diberikan perhatian yang lebih besar guna meningkatkan pendapatan petani dan kesejahteraan petani. Bila sektor pertanian dan nonpertanian akan dikembangkan maka informasi dasar mengenai kegiatan pertanian dan nonpertanian 
dalam skala yang lebih luas, baik dari cakupan wilayah penelitian maupun aspek yang diteliti perlu diketahui.

Emansipasi perempuan dewasa ini sering dibicarakan dalam masyarakat, terutama pada masyarakat timur. Keinginan perempuan untuk maju mensejajarkan dirinya dengan kaum pria telah mendorong perempuan untuk memperoleh kesempatan kerja yang sama dengan pria di segala bidang, sekalipun factor-faktor sosiologis, adat dan budaya merupakan nilai hidup dan makna kesusilaan tetap mewarnai peranannya sebagai perempuan.

Sebagai individu, perempuan juga memiliki harapan-harapan, kebutuhankebutuhan, minat dan potensi yang menekankan nilai positif manusia. Perempuan juga membutuhkan aktualisasi diri yang seoptimal mungkin demi pengembangan dirinya, sesuatu pada akhirnya juga membawa dampak positif pada pengembangan umat manusia secara umum. Perempuan yang jumlahnya lebih dari setengah jumlah penduduk dapat menjadi sumber daya manusia yang sangat potensial bagi pembangunaan masyarakat dan bangsa. Aktulisasi perempuan sebagai sumber daya dalam masyarakat dan pengembangan diri perempuan hanya akan terjadi dalam situasi kondisi lingkunganlmasyarakat yang kondusif, yang memang memungkinkan hal tersebut terjadi (Poewandari dalam T.O. Ihromi, 2005 : 315)

\section{Permasalahan}

Berdasarkan pendahuluan yang telah diuraikan di atas dapat dirumuskan permasalahan sebagai berikut : Bagaimanakah kondisi Pendapatan Wanita di Kelurahan Paal V Kecamatan Kotabaru Jambi serta apa saja faktor-faktor yang mempengaruhi pendapatan Wanita di Kelurahan Paal V Kecamatan Kotabaru Jambi.

\section{B. LANDASAN TEORITIS}

\section{Analisis Pekerja Perempuan}

Ada suatu kontinuitas dalam perhatian mengenai statusl keadaan perempuan di Indonesia dari setengah abad yang lalu sampai sekarang. Kalau dahulu perhatian terutama ditunjukan kepada persoalan persamaan hak dalam konteks peranan perempuan sebagai istri dan ibu, sekarang perhatiannya berkisar kepada persoalan integrasi sepenuhnya dalam usaha pembangunan dalam konteks peranannya sebagai sumber daya manusia. 
Menurut Soetanto (1998 : 54) meningkatkau peranan perempuan dalam pembangunan berarti suatu usaha untuk mengembangkan sumber daya manusia. Mengingat manusia itu sendiri adalah sekaligus subjek, objek dan penikmat hasil pembangunan. Karena itu bila Negara menuntut agar peran perempuan dalam pembangunan meningkat, ini berarti perempuan dituntut mempunyai kemampuan untuk dapat mengembangkan potensi yang ada pada dirinya. Sehingga secara nyata untuk perempuan itu mempunyai hak, kewajiban dan kesempatan yang sama dengan pria.

Usaha-usaha perempuan untuk memperoleh kesempatan yang sama seperti yang terbuka bagi pria belakangan ini merupakan bahan pembicaraan yang menarik. Terlepas dari pertimbangan nilai-nilai atau keadaan ekonomi dari semula dapat diduga bahwa jumlah kesempatan yang terbuka bagi kaum perempuan untuk dapat berpartisipasi dalam angkatan kerja lebih sedikit, jika dibandingkan dengan yang ada untuk kaum pria (Sayogyo, $2001: 11$ )

Susyanto (1996 : 85) menyatakan ada dua alasan yang dapat dikemukakan dari pertanyaan mengapa keinginan pembangunan di Indonesia harus sering dengan pemberdayaan perempuan. Pertama, karena perempuan sesungguhnya memang sejumlah fungsi sentral dalam keluarga, dan sekaligus merupakan sumberdaya ekonomi yang tidak kalah penting dibandingkan dengan pria. Keberadaan perempuan dalam rumah tangga bukan sekedar pelengkap reprodusi saja, namun lebih dari itu banyak penelitian yang membuktikan bahwa perempuan ternyata seringkali memberikan sumbangan yang besar bagi kelansungan ekonomi dan kesejahteraan rumah tangga serta masyarakat. Kedua, karena selama ini keterlibatan atau tingkat partisipasi kerja (TPK) perempuan pada umumnya masih sangat rendah, sehingga ada kesan perempuan justru menjadi beban dalam pembanggunan. Kendati menurut hasil statistic yang ada dibandingkan dengan TPAK pria pada umumnya masih ketinggalan. Ini berarti jumlah tenaga kerja perempuan yang terlibat dalam pasar kerja hanya sekitar separuh dari jumlah pria.

Menurut Moser (dalam Suyanto, 1996 : 86) bahwa inti strategi pemberdayaan (empowerment) sesungguhnya bukan bermaksud menciptakan perempuan yang lebih unggul daripada pria. Pendekatan pemberdayaan ini kendati menyadari pentingnya meningkatkan kekuasaan perempuan, namum pendekatan ini lebih berupaya untuk 
mengidentifikasi kekuasaan bukan sekedar dalam kerangka dominasi yang satu terhadap yang lain, melainkan dalam rangka kapasitas perempuan untuk meningkatkan kemandirian dan kekuatan internal.

Jika dalam suatu pasar kerja terdapat suatu keadaan dimana dalam jenis pekerjaan yang sama pekerjaan mendapat pula upah yang berbeda, dan dalam ha1 ini semata-mata disebabkan oleh perbedaan jenis kelamin, kesukuan, kekeluargaan, kedaerahan, keanggotaan dalam suatu kelompok strategis tertentu serta factor-faktor lain, maka disitulah terdapat segmentasi pasar kerja (Evers dalam Sukidin, 2000 :149). Dalam konteks teori segmentasi, pasar tenaga kerja terbagi kedalam beberapa segmen. Setiap segmen diisi oleh buruh yang memiliki karakteristik tertentu dan mendapat upah yang berbeda. Salah satu pandangan tentang segmentasi tenaga kerja adalah pandangan dualis dari Doeringer dan piorre (Indraswari, 1994 : 11) yang membagi pasar tenaga kerja dalam dua segmen yaiyu pasar primer dan pasar sekunder. Pasar primer ditandai dengan adanya angkatan kerja yang berketerampilan tinggi, berubah tinggi, posisinya dalam perusahaan terlindungi, dan kondisi pekerjaan yang baik. Pasar sekunder ditandai dengan angkatan kerja kurang trampil atau setengah tera.mpil, berrubah rendah, posisi dalam perusahaan tidak stabil dan kondisi kerja kurang baik (Saptari dalam Indraswari, 1994: 11).

Dari aspek gender pasar primer banyak diisi oleh tenaga kerja laki-laki, sementara pasar sekunder lebih banyak diisi oleh perempuan. Hal itu disebabkan karena kemampuan kerja perempuan dinilai rendah, secara social perempuan berbeda dengan pria, perempuan memiliki komitmen rendah dalam peningkatan karir karena orientasi dan tanggung jawab mereka lebih terfokus pada pekerjaan domestic, mereka di nilai sebagai makluk yang tidak terlalu berambisi mendapatkan upah tinggi serta solidaritas perempuan dianggap rendah (Barron dan Norris dalam Indraswari, 1994 : 12), Dengan semua masalah tersebut, perempuan dipandang lebih sesuai mengisi sector, sekuder daripada sector primer. Maksuknya perempuan kedalam pasar kerja sekunder secara tidak langsung telah memarginalkan posisi perempuan dalam pasar kerja.

Untuk melihat mengapa perbedaan upah itu bias terjadi, teori gender menjelaskan bahwa kedudukan perempuan dalam pasar tenaga kerja dan di dalam rumah tangga atau keluarga bertalian satu sama lain yang merupakan bagian integral 
dari keseluruhan system social. Namun dalam realitasnya perempuan memiliki kedudukan yang lebih rendah dihadapan laki-laki, baik perannya dalam keluarga maupun posisinya sebagai pekerja.

Menurut Arief Budiman (1998 : 85) Perbedaan upah terjadi karena perempuan ditempatkan sebagai penghasil sekunder dari pendapatan rumah tangga secara keseluruhan. Penepatan perempuan dalam posisi seperti ini diakibatkan oleh adanya alasan ideology, dimana nilai-nilai yang ada pada masyarakat yang cenderung mensubordinasi pekerja perempuan. Mitos ini terus berkembang dengan menganggap tenaga kerja laki-laki sebagai kepala keluarga sehingga bertanggung jawab sebagai pencari nafkah utama dan bila perempuan bekerja dianggap sebagai factor pelengkap saja.

Menurut Scott (Indrawari, 1994 : 12) marginalisasi perempuan tumbuh dari kombinasi factor sejarah, ekonomi dan budaya dalam arti luas, tidak hanya disebabkan oleh suatu system ekonomi politik tertentu. Dengan pemahaman tersebut, marginalisasi bisa terjadi pada berbagai kelompok masyarakat berdasarkan gender, etnis dan kelas. Proses marginalisasi mengakibatkan perempuan lebih tersisih dibandingkan laki-laki, sehingga mengakibatkan perempuan harus menyadarkan kehidupannya pada samber-suber marginal dalam periferi ekonomi pasar.

Selanjutnya Becker (dalam Febrero dan Schwartz, 2000) menge-mukakan pendekatan baru teori alokasi waktu dengan perbedaan kegiatan. Tanggapan Becker terhadap teori Gronau yaitu bahwa total waktu dibedakan atas waktu produktif yang benar-benar digunakan untuk bekerja (productive working time) dan waktu produktif (productive time) yang digunakan untuk santai (leisure) seperti nonton TV dan aktivitas lain (work at home or not work). Becker membedakan kegunaan waktu berdasarkan berapa biaya per jam (cost/hour) setiap aktivitas yang dilakukan. Oleh karena itu waktu digunakan saat ini lebih hati-hati daripada waktu yang lalu.

\section{Tingkat Partisipasi Angkatan Kerja (TPAK) Perempuan}

Keikitsertaan perempuan dalam kegiatan pembangunan berarti memanfaatkan suber daya manusia yang berpotensi. Pengembangan sumber daya manusia yang bertujuan untuk mengarahkan dan membina sumber daya tersebut kearah yang lebih produktif. Peranan dan kedudukan perempuan dalam kehidupan masyarakat ternyata tidak dapat diabaikan antara lain sebagai penyongkong kehidupan rumah tangga 
(Sayogyo dalam Suandi, 2001:206). Lebih lanjut ditegaskan bahwa perempuan mempunyai dua posisi atau status dalam kegiatan bekerja yaitu dalam pekerjaan rumah tangga dan pekerjaan yang menghasilkan pendapatan langsung.

Ahli ekonomi mengemukakan beberapa alasan untuk menjelaskan kenaikan tingkat partisipasi angkatan kerja perempuan :

\section{a. Kenaikan upah riil perempuan}

Dalam jangka panjang terdapat kenaikan pada upah riil bagi perempuan yang memperoleh pendapatan dipasar kerja. Ini merupakan awal dari sebuah konsekuensi bagi perempuan yng mempunyai keahlian melalui pendidikan. Suatu kenaikan upah bagi perempuan menikah mempunyai pengaruh pendapatan maupun pengaruh subsitusi. Menurut Ballente (1993 : 113) mengemukakan bahwa kenaikan upah rill perempuan menaikan juga rangsangan rumah tangga untuk menggantikan komoditi barang-barang intensif dengan komoditi waktu intensif dalam hal konsumsi. Baik penggantian produksi maupun konsumsi yang berlangsung sebagai akibat dari kenaikan tingkat upah perempuan pekerja cenderung menaikan jumlah waktu yang digunakan oleh perempuan menikah untuk melakukan kegiatan di pasar kerja.

\section{b. Perubahan Preferensi dan Perilaku}

Kenaikan tingkat partisipasi perempuan juga merupakan akibat dari perubahan fundamental dalam pasar tenaga kerja. Gerakan kaum feminis berpengaruh pada karir objektif yang mengarahkan perempuan terhadap pasar tenaga kerja perempuan. Tingginya tingkat pendidikan perempuan juga memungkinkan terjadinya peningkatan terhadap "selera" atau preferensi mereka pada karir di pasar tenaga kerja. Secara umum prilaku masyarakat tentang perempuan bekerja cepat berubah. Oleh karena itu tingkat pendidikan dan kegairahan bekerja saling berkaitan secara positif, maka kecenderungan kembali ke pasar kerja yang tidak berhubungan dengan uang menjadi meningkat di kalangan perempuan bersuami, sehingga mendorong ke arah peningkatan partisipasi (Ballente, 1993 :113).

\section{c. Kenaikan Produktivitas Rumah Tangga}

Pengunaan teknologi oleh para penguasa merupakan faktor penting dalam meningkatkan produktivitas terhadap jam kerja dan meningkatkan tingkat upah rill. 
Kemajuaan barang-barang modal yang lebih baik untuk rumah tangga akan mengurangi sejumlah waktu yang dibutuhkan untuk menyelesaikan produksi dan menkonsumsi di rumah. Kemajuan-kemajuan ini telah menciptakan kemungkinan terjadinya, subsitusi terhadap barang-barang pasar dengan waktu dalam produksi rumah tangga. Para istri telah memilih untuk menarik keuntungan dari kemajuankemajuan ini bukan dengan cara menaikan produksi barang-barang rumah tangga atau dengan menambah waktu senggang atau pendidikan tambahan, akan tetapi melalui penambahan partisipasi dalam kegiatan pasar (Ballente, 1993 : 115).

\section{d. Penurunan Tingkat Kelahiran}

Kehadiran anak-anak di dalam rumah tangga cenderung mengurangi semangat partisipasi angkatan kerja di kalangan perempuan bersuami. Keperdulian terhadap anak membutuhkan waktu intensif yang tinggi sehingga mengurangi aktivitas istri yang beberapa diantaranya malah keluar dari pasar kerja. Walaupun baby sister, perawat, suami dan pusat pemeliharaan anak dapat mensubsitusikannya, namun biaya oportunitasnya seringkali menjadi subsitusi yang rumit.

Di lain pihak meluasnya persedian dan pengunaan teknik pengaturan bayi digabungkan dengan perubahan gaya hidup akan mengurangi tingkat kelahiran yang membutuhkan banyak waktu. Bagaimanapun juga penekanan pada masalah waktu yang $b ® n y a k$ pada mat melahirkan menyebabkan banyak perempuan absen dari pasar tenaga Ieija untuk menjalankan tangging jawabnya. Maka dari itu mereka berfikir lebih baik jika mareka mengejar karir di pasar kerja.

\section{e. Tingginya Tingkat Perceraian}

Ketidakstabilan perkawinan menaikan tingkat peceraian yang dimotivasi dengan loeyakinan menyebabkan beberapa perempuan memelihara pasar kerjanya. Tingkat peceraian semakin meningkat dengan cepat dalam dekade terakhir. Pengaruh ekonomi dari peceraian perempuan seringkali dikarnakan relatif sedikit perempuan yang menerima uang pemeliharaan atau pembayaran untuk anak-anak dari suami mereka, jaga sering adanya pilihan antara kemiskinan, kesejahteraan atau bekerja di pasar kerja. Banyaknya perempuan menikah yang tidak memikirkan perkawinannya dan memilih berpartisipasi di pasar kerja berarti melindungi diri mereka sendiri dari kebutuhan lrevangan terhadap perceraian. 
Meningkatnya kemungkinan tingkat peceraian akan cenderung memperkecil tmgkat kelahiran sebab perawatan anak akan sangat sulit setelah sebuah perkawinan terpisah. Sebaliknya kehadiran sedikit atau tidak adanya anakanak akan mengurangi sakit akibat perceraian dan juga mengurangi biaya.

\section{f. Perluasan Kemampuan Kerja}

sebagai tambahan untuk penurunan diskriminasi gender, sebuah perubahan dari faktor lain membuat pekerjaan lebih mudah dimasuki oleh perempuan. Pertama, sejak Perang Dunia II terdapat perluasan yang besar secara absolut dan relatif dalam jenis pekerjaan tradisional sebagai pekerjaan perempuan. Kedua, terdapat pergeseran populasi dalam jangka panjang dari pertanian dan kawasan pedesaan ke wilayah kota, dimana pekerjaan perempuan lebih banyak dan lebih mudah untuk dimasuki secara geografis. Ketiga, rata-rata panjangnya pekerjaan mingguan y;ang penuh waktu berkurang dan kemampaun dari pekerjaan part time meningkat. Hal yang membuat kemudahan bagi perempuan adalah menyepakati antara pekerj aan di pasar kerja dengan pekerjaan mengurus rumah tangga.

\section{g. Pemeliharaan Standar Hidup}

Perhunbuhan Pendapatan laki-laki pada dua dekade yang lalu cenderung tetap dibandingkan pada dekade sebelumnya. Kenyataannya untuk beberapa lakilaki tetutama pekerja dengan upah rendah, keuntungan riil secara mingguan adalah rendah pada saat ini.

Beberapa rumah tangga menyesuaikan keadaan itu dengan kedua suami isteri bekerja, sehingga mereka dapat memsubstitusikan waktu yang ada di pasar kerja terhadap waktu untuk memproduksi di rumah tangga untuk memelihara standar hidup keluarga yang secara absolut dan relatif juga terjadi untuk rumah tangga lainnya ( Johson dan Skinner dalam Mc Connel, 1999 : 71).

Sebagian dari kenaikan pada tingkat partisipasi angkatan kerja perempuan dipaksa oleh keadaan keluarga yang bermaksud "menahan kemiskinan". Dalam beberapa kasus "menahan kemiskinan" implikasinya pada pembayaran untuk makanan, pakaian dan perlindungan. Pada kasus lainnya berarti pemeliharaan pada gaya hidup kelas menengah maupun kelas atas. 


\section{METODE PENELITIAN}

\section{Model Analisis}

Untuk dapat menjelaskan peran perempuan khususnya bagi yang telah menikah baik dalam kehidupan rumah tangga maupun didalam kehidupan masyarakat, sesuai dengan panca tugas perempuan sebagai istri pendamping suami, sebagai pendidik dan Pembina generasi muda, sebagai ibu rumah tangga, sebagai tenaga kerja dan sebagai anggota organisasi masyarakat, diperlukan gambaran perilaku istri dalam mengalokasikan waktu dan tenaga. Pemanfaatan waktu dari perempuan mencerminkan bagaimana ia dapat menyediakan waktunya untuk berbagai kegiatan sehari-hari, dimulai dari kegiatan di pasar kerja untuk kegiatan social serta untuk waktu senggang (santai).

Model yang digunakan untuk melihat hubungan antara faktor-faktor penting dengan Pendapatan Wanita (PW) dirumuskan dalam sebuah fungsi sebagai berikut :

$$
\mathrm{PW}=\mathrm{f}(\text { P SP JK Ys) }
$$

PW = Pendapatan wanita

$\mathrm{P} \quad=$ Pendidikan

SP $\quad=$ Status Perkawinan

$\mathrm{Jk} \quad=$ Jumlah anggota keluarga (iiwa)

Ys = Besarnya pendapatan kepala keluarga

Selanjutnya agar fungsi di atas dapat diestiminasi, maka fungsi tersebut dibuat dalam bentuk persamaan linier yang dapat ditulis sebagai berikut :

$$
\mathrm{PW}=\mathrm{a}_{\mathrm{o}}+\mathrm{a}_{1} \mathrm{P}+\mathrm{a}_{2} \mathrm{SP}+\mathrm{a}_{3} \mathrm{JK}+\mathrm{a}_{4} \mathrm{Ys}+\mathrm{e}_{1}
$$

Dimana :

$$
\begin{array}{ll}
\mathrm{PW} & =\text { Pendapatan wanita yang merupakan wariabel dependen } \\
\mathrm{a}_{\mathrm{o}} & =\text { Konstanta } \\
\mathrm{a}_{1} \ldots \mathrm{a}_{4} & =\text { Parementer } \\
\mathrm{P} & =\text { Pendidikan } \\
\mathrm{SP} & =\text { Status Perkawinan } \\
\mathrm{SP} & =1 \text { untuk perempuan yang menikah } \\
\mathrm{SP} & =0 \text { untuk lainnya } \\
\mathrm{Jk} & =\text { Jumlah anggota keluarga (jiwa) } \\
\mathrm{Ys} & =\text { Besarnya pendapatan kepala keluarga per bulan (Rp) } \\
\mathrm{E}_{1} & =\text { Kesalahan Pengganggu (disturbance) }
\end{array}
$$

Untuk melinearkan fungsi di atas maka perlu dilakukan penghalusan (smoothing) hal ini dikarenakan satuan dari variabel penelitian kemungkinan tidak 
sama oleh karena itu fungsinya dibuat dalam bentuk logaritma yang dapat ditulis sebagai berikut .

$$
\log \mathrm{PW}=\mathrm{a}_{\mathrm{o}}+\mathrm{a}_{1} \log \mathrm{P}+\mathrm{a}_{2} \operatorname{LogSP}+\mathrm{a}_{3} \operatorname{LogJK}+\mathrm{a}_{4} \log \mathrm{Ys}+\mathrm{e}_{1}
$$

\section{Hasil Penelitian}

\section{a. Hasil Estimasi Untuk Wanita Menikah}

Untuk menjelaskan hasil curahan waktu wanita menikah, digunakan model persamaan regresi sebagai berikut :

$$
\log \mathrm{PW}=\mathrm{a}_{\mathrm{O}}+\mathrm{a}_{1} \log \mathrm{TP}+\mathrm{a}_{2} \log \mathrm{JK}+\mathrm{a}_{3} \log \mathrm{Ys}+\mathrm{e}_{1}
$$

Hasil estimasi model adalah sebagai berikut :

$$
\operatorname{LogPW}=105,989+3,276 \mathrm{TP}+0,455 \mathrm{JK}-0,0000001218 \mathrm{Ys}
$$

Secara parsial pengaruh setiap variable bebas terhadap variable tidak bebas dapat dilihat pada table berikut ini :

Tabel Hasil Estimasi Pendapatan Wanita Menikah Di Kota Jambi

\begin{tabular}{|l|l|l|l|l|l|}
\hline $\begin{array}{l}\text { Nama } \\
\text { Variabel }\end{array}$ & $\begin{array}{l}\text { Koefisian } \\
\text { Estimasi }\end{array}$ & T-Ratio & T-Tabel & Alpha & $\begin{array}{l}\text { Stansar } \\
\text { Error }\end{array}$ \\
\hline TP & 3,276 & 2,264 & 1,960 & 0,05 & 1,043 \\
\hline JK & 0,44 & 1,435 & 1,282 & 0,10 & 1,047 \\
\hline YS & - & $-1,040^{*}$ & & & 0,000 \\
\hline Konstanta & 10,0000001218 & & & & 1,960 \\
\hline $\begin{array}{l}\mathrm{R}=0,909 \\
\mathrm{R}^{2}=0,826 \\
\mathrm{R}^{2}(\text { Adj })=0,805\end{array}$ & 9,643 & $1,960,005$ & 10,991 \\
\hline
\end{tabular}

Sumber: Lampiran 2

$$
: *)=\text { tidak Signifikan }
$$

\section{b. Hasil Estimasi Untuk Wanita Belum Menikah}

Untuk menjelaskan faktor-faktor yang mempengaruhi Pendapatan (PW) bagi wanita belum menikah di Kelurahan Paal V Kecamatan Kotabaru, maka digunakan persamaan yang sama dengan persamaan pada model wanita belurn menikah yaitu :

$$
\log \mathrm{PW}=\mathrm{a}_{\mathrm{O}}+\mathrm{a}_{1} \log \mathrm{TP}+\mathrm{a}_{2} \log \mathrm{JK}+\mathrm{a}_{3} \log \mathrm{Ys}+\mathrm{e}_{1}
$$

Hasil estimasi model adalah sebagai berikut :

$$
\operatorname{LogPW}=105,989+3,276 \mathrm{TP}+0,455 \mathrm{JK}-0,0000001218 \mathrm{Ys}
$$

Secara parsial pengaruh setiap variable bebas terhadap variable tidak bebas dapat dilihat pada table hal 50.. : 
Tabel Hasil Estimasi Pendapatan Wanita Belum Menikah di Kecamatan Kota Baru

\begin{tabular}{|l|l|l|l|l|l|}
\hline $\begin{array}{l}\text { Nama } \\
\text { Variabel }\end{array}$ & $\begin{array}{l}\text { Koefisian } \\
\text { Estimasi }\end{array}$ & T-Ratio & T-Tabel & Alpha & $\begin{array}{l}\text { Stansar } \\
\text { Error }\end{array}$ \\
\hline TP & 7,523 & 2,823 & 1,960 & 0,05 & 2,665 \\
\hline JK & 5,762 & 2,065 & 1,190 & 0,05 & 2,791 \\
\hline YK & $-0,0000003242$ & $-1,508$ & 1,282 & 0,10 & 0,000 \\
\hline Konstanta & 12,212 & 0,474 & & 0,05 & 25,745 \\
\hline $\begin{array}{l}\mathrm{R}=0,963 \\
\mathrm{R}^{2}=0,927\end{array}$ \\
$\mathrm{R}^{2}($ Adj $)=0,911$ & $\begin{array}{l}\text { F-hitung }=173,691 \\
\text { DW }=2,029\end{array}$ \\
\hline
\end{tabular}

Sumber: Lampiran 3

\section{Implikasi Penelitian}

Jika penelitian ini dilihat secara umun antara wanita menikah, wanita belum menikah dan secara keseluruhan dapat digambarkan melalui Tabe14.9 berikut ini:

\section{Tabel Nilai Estimasi Secara Umum Untuk Pendapatan \\ Wanita di Kelurahan Paal V Kecamatan Kotabaru}

\begin{tabular}{|c|c|c|c|}
\hline \multirow{2}{*}{$\begin{array}{c}\text { Nama } \\
\text { Variabel }\end{array}$} & \multicolumn{3}{|c|}{ Nilai Koefesian Estimasi } \\
\cline { 2 - 4 } & $\begin{array}{c}\text { Wanita } \\
\text { Keseluruhan }\end{array}$ & Wanita Menikah & $\begin{array}{c}\text { Wanita Belum } \\
\text { Menikah }\end{array}$ \\
\hline TP & $1,842^{* *}$ & $3,276^{* *}$ & $7,523^{* *}$ \\
\hline SP & $14,434^{\wedge}$ & - & - \\
\hline JK & $1,107^{* *}$ & $0,455^{* * *}$ & $5,762^{* *}$ \\
\hline YS & $-0,0000003698^{* * * *}$ & $-0,0000001218^{* * * *}$ & $-0,000003242^{* * *}$ \\
\hline
\end{tabular}

Sumber : Data Hasil Analisis

*) = Signifikan pada alpha 0,01

**) = Signifikan pada alpha 0,05

$* * *) \quad=$ Signifikan pada alpha 0,10

$* * * *)=$ Tidak Signifikan

\section{KESIMPULAN}

Berdasarkan pembahasan dan hasil penelitian, maka dapat disimpulkan bahwa :

Faktor-faktor yang secara signifikan mempengaruhi Pendapatan wanita (PW) pada wanita keseluruhan, wanita menikah dan wanita belum menikah adalah variabel pendidikan, variabel status perkawinan dan variable jumlah anggota keluarga pada tingkat keyakinan 99\% dan 95\%. Sedangkan untuk variable pendapatan kepala keluarga dalam penelitian ini tidak signifikan serta berdasarkan hasil estimasi, faktor yang dominan terhadap bertambahnya pendapatan wanita (PV) di Kecamatan Kotabaru adalah 
variabel status perkawinan, variabel pendidikan dan variabel jumlah anggota keluarga. Sedangkan nilai estimasi yang mengurangi Pendapatan wanita (PW) adalah variable pendapatan kepala keluarga/suami, baik pada wanita menikah, wanita keseluruhan, akan tetapi tidak pada wanita yang belum menikah karena nilai estimasinya positif. Untuk menunjukkan hubungan dan variasi model yang digunakan maka dapat disimpulkan dari seluruh estimasi ketiga macam model rata-rata koefisien derterminasi $\mathrm{R}^{2}$ diperoleh nilai 0,879 yang berarti 87,9 persen variable pendidikan, status pernikahan, jumlah anggota keluarga, pendapatan kepala keluarga/suami dapat mempengaruhi Pendapatan wanita di Kecamatan Kotabaru Jambi, sedangkan sisanya sebesar 12,1 persen diterangkan oleh variable lain yang tidak dimasukkan dalam penelitian ini.

\section{DAFTAR PUSTAKA}

Arief, Sritua (2003), Metodologi Penelitian Ekonomi", Lembaga Penerbit Universitas Indonesia, Jakarta

Arsyad Lincolin (2002), Ekonomi Pembangunan, UGM, Bagian Peneritan Sekolah Tinggi Ilmu Ekonomi YKPN, Yogyakarta

Ballente, Don and Mark Jackson (1993), Ekonomi Ketenagakerjaan, Lembaga penerbit Fakultas Ekonomi Universitas Indonesia, Jakarta

Baroleh,J.V.V. Rntung, O.Porajouw,M.F.L. Sondakh, (1998), Karakteristik Angkatan Kerja Perempuan di Sulawesi Utara, Analisis Data Sensus 1990, Jurnal Samratulangi Universitas, Vo1.XVIII No.17 Februari 1998, Penerbit Lembaga Penelitian Universitas Samratulangi, Manado

Boseruf,Ester,(2000), Peranan Perempuan dalam Pembangunan Eknomi, Penerbit Yayasan Obor Indonesia, Jakarta

Ihromi,T.O,(2005), Kajian perempuan dalam Pembangunan, Penerbit Yayasan Obor Indonesia, Jakarta

Indraswari dan Thamrin,(1994), Potret Kerja Buruh Perempuan, Tinjauan pada Agroindustri Tembakau Ekspor di Jember Penerbit Yayasan Akatiga Bandung

Mc. Connel,Campbell,R,Stanley L. Brue,David A. Machperson,(1999), Contem-porary Labour Economics, Penerbit Mc Graw-Hill International Edition, Fifth Edition, SanFransisco

Momsen,Janet Henshall,(1991),Women And Development In The Third World, Division of Routledge, Chapman and Hall, Inc, NewYork 
J URNAL DEVELOPMENT

Nopiriu, (2003),Ekonomi Moneter, Jilid II Edisi I, BPFE, Yogyakarta

Sayogyo,P.(2001) Peranan Perempuan Dalam Pembangunan Masyarakat Desa, Penerbit CV. Rajawali, Jakarta 